\title{
Segmentation of Parmigiano Reggiano dairies according to cheese-making technology and relationships with the aspect of the cheese curd surface at the moment of its extraction from the cheese vat
}

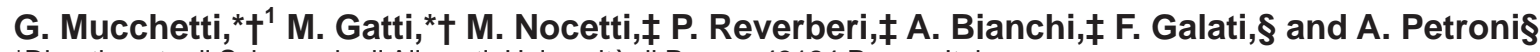 \\ ${ }^{*}$ Dipartimento di Scienze degli Alimenti, Università di Parma, 43124 Parma, Italy \\ †Centro Multidisciplinare Interdipartimentale Lattiero Caseario, Università degli Studi di Parma, Parma, Italy \\ ¥Consorzio del Formaggio Parmigiano Reggiano, 42100 Reggio Emilia, Italy \\ §Dipartimento di Ingegneria Industriale, Università di Parma, 43124 Parma, Italy
}

\begin{abstract}
Parmigiano Reggiano cheese dairies develop specific cheese-making strategies to adapt the variable characteristics of raw, not standardized milk to the final goal of obtaining cheese consistent with the standard. Analyzing 1,175 cheese-making reports from 30 out of 383 dairies associated with the Parmigiano Reggiano Consortium in 2010 and 2011, 4 groups of Parmigiano Reggiano dairies using specific cheese-making technologies were discriminated by means of multiple linear discriminant analysis. Cheese makers manage cheese-making practices to obtain curd with different roughness properties, classified according to jargon words such as "rigata" and "giusta" or synonyms, because they believe that the roughness of the cheese curd surface immediately after the extraction from the vat is associated with different whey-draining properties and to the final outcome of the cheese. The aspect of the surfaces of the curds produced by the 4 groups of dairies was different according to the technology applied by each group. Cutting of the coagulum when it is still soft for a longer time and faster cooking of the cheese curd grains were associated with a less rough appearance of the surface of the curd, whereas under the opposite conditions, cutting the coagulum when it is firm for a shorter time, led to a curd with a rougher surface. These findings partially support the traditional feeling of Parmigiano Reggiano cheese makers, who consider the curd surface aspect one of the main drivers for their technological choices; to date, however, no data are provided about correlation between the aspect of the curd and the quality of the ripened cheese. If a sufficiently strong correlation could be demonstrated by the future development of the research, the operational effectiveness of Parmigiano Reggiano dairies will be able to
\end{abstract}

Received May 14, 2013.

Accepted November 27, 2013.

${ }^{1}$ Corresponding author: germano.mucchetti@unipr.it largely benefit from the availability of sound and early process markers.

Key words: Parmigiano Reggiano cheese-making technology, dairies segmentation, cheese curd surface aspect

\section{INTRODUCTION}

An overall definition of Parmigiano Reggiano (PR-RE) cheese-making technology and cheese characteristics is given by protected designation of origin (PDO) European Regulation (DOOR, 2013). Parmigiano Reggiano is a very hard, long-ripened cheese characterized by a fine-grained structure, resulting from its specific cheese-making technology (Noel et al., 1996; Gobbetti, 2007). Basically, PR-RE cheese-making technology is the result of the sound combination of the following parameters: use of raw milk partially skimmed by overnight spontaneous creaming mixed with the whole milk from the morning milking, addition of a whey starter culture mainly composed of indigenous thermophilic lactic acid bacteria to lower the cheese milk $\mathrm{pH}$ at renneting, milk coagulation with animal rennet into a copper vat with capacity of about $1.0 \mathrm{t}$ of milk, judging the hardness of the coagulum manually by touching it with the fingers, cutting of soft coagulum with a specific tool called "spino," fast cooking of curd grains to temperature of about 55 to $56^{\circ} \mathrm{C}$, and resting of the cooked curd under the hot whey for about 60 min. (Gatti et al., 2003; Mucchetti and Neviani, 2006; Malacarne et al., 2008; Pecorari et al., 2009; Iezzi et al., 2012; Gatti et al., 2014). As milk standardization is prohibited by PDO rules, producers have to contrast variability through fine tuning efforts to make cheese-making parameters adherent to milk quality. Furthermore, PR-RE cheese-making standard prevents automation and a strong industrialization of processes (Mucchetti and Neviani, 2006). The more relevant process innovation introduced by some dairies in the last decade is the partial mechanization of the cutting of coagulum (Iezzi et al. 2012). 
Consequently, PR-RE production, though preserving its standards of identity, can be defined as highly dairy specific and relies upon the set of skills and competencies accumulated by producers through experience and tacit knowledge. In the present paper, we have tried to address the basic question of whether and under what criteria it may be possible to operate an effective discrimination among technologies and production processes of dairies associated with the PR-RE Consortium.

Monnet et al. (2000) used edaphic or sensory criteria to discriminate Comté PDO cheeses produced by 20 dairies located in the Jura region in relation to their geographical origin ("georegions" or terroirs). Those authors grouped dairies into 8 clustering types based on the sensory similarities of their cheeses, concluding that taste variations of cheese were significantly and to a large extent could be traced back to soil variations. Bittante et al. (2011) evaluated the internal structure of Trentingrana cheeses through the sound produced by beating the wheel with a special hammer, demonstrating that average scores were inversely associated with the size of the dairies.

It is a common and traditional belief in the production area of PR-RE cheese that some of the best final structural cheese characteristics are largely dependent on the fresh cheese curd properties. Parmigiano Reggiano cheese makers usually evaluate the results of the cheese-making procedure on the basis of the aspect of the curd surface immediately after its extraction from the vat. Curd surface, however, is not homogeneous, and when dipped into whey it can be divided into 4 main areas: (1) bocca (mouth), the upper surface of the curd at contact with the hot whey; (2) bottom, the symmetrically opposite area; (3) side, the part of the curd at contact with the hot inclined side of the vat; and (4) cut, the part of the curd corresponding to the zone where the whole mass will be divided in 2 parts with a knife at the moment of its extraction (Pecorari, 2011).

Parmigiano Reggiano cheese makers traditionally qualify the aspect of cheese curd surfaces at the extraction from the vat using jargon words, such as "rigata," "giusta," "finita," or "appostata," that are rarely communicated in the literature (Cattaneo, 1837; Quadri, 1959; Parisi, 1966; Pecorari, 2011) or explained to other people. Rigata literally means "lined or striped," and, when referring to the side of the curd immediately after the extraction, rigata specifies a structure characterized by horizontal alternating zones with different rough morphology. When referring to the bocca, rigata means that the surface is randomly rough, but without stripes. Some authors apply the word rigata only to the side of the curd (Pecorari, 2011). Giusta, finita, or appostata literally mean "right" or "completed," and these adjectives are used to represent a curd with a smooth surface, given by an overcooking of cheese curd grains with too reduced a size. These words summarize an intellectual property and the individual ability to manage a traditional process, and are often also used to classify the overall cheese-making technology.

If not better specified, the definition of the smoothness of the surface of PR-RE may lead to some misunderstanding. When PR-RE cheese makers or technicians refer to a smooth surface they use a relative scale, as smoothness of the PR-RE surface is lower than many other cheeses where curd grains fuse themselves. Smoothness of PR-RE is related to the size of the cooked curd grains, as they have a reduced size, with a mean projected area of $1.31 \pm 0.93 \mathrm{~mm}^{2}$, smaller than that of Cheddar or Gouda cheeses (Iezzi et al., 2012). Different from other cooked cheeses, the fine-grained structure of ripened PR-RE cheese has to be perceived by the consumer, and, therefore, cooked curd grains need to aggregate themselves, but without a complete fusion, retaining their individuality (Gobbetti, 2007).

The current paper presents the results of research carried out with the objective to test and validate statistical approaches to discriminating PR-RE dairies according to dairy-specific cheese-making technologies. Moreover, it strives to provide empirical evidence of the possibility of profiling different types of production of cheese curds based on the association of technology to the various aspect features as recorded at the moment of extraction from the cheese vat.

\section{MATERIALS AND METHODS}

\section{Data Set}

Cheese-making parameters were monitored between 2010 and 2011 in 30 PR-RE dairies out of 383 dairies in operation that have been authorized for PR-RE cheese production. Dairies were selected by a random choice, taking care that dairies from each district belonging to the PR-RE area were in the sample. Observations have been replicated from 33 to 54 times per dairy, repeating the monitoring the same day for different vats and over time. A total figure of 1,175 cheese-making reports were obtained and investigated. Twenty-seven cheese-making parameters were measured or calculated per dairy and are listed in Table 1. To compare the amount of rennet used (g/100 kg of milk), its strength was normalized to a common value of 100,000 (i.e., 1 part of rennet coagulates 100,000 parts of milk).

Besides these parameters, 2 curd properties were monitored by 8 trained technicians, who evaluated the aspect of the surface of cheese curds immediately after 
the extraction from cheese vat on a 5-item scale, with separate judgments of the upper side (bocca) and the side. Scale items corresponded, in increasing numerical order (1-5), to "very rough and lined" (1), "rough and lined" (2), "slight rough and lined" (3), "smooth" (4), and "irregularly rough with cavities" (5).

\section{Grouping of Dairies According to Cheese-Making Technologies by Means of Multiple Linear Discriminant Analysis}

The objective of the analysis is the identification of differences in the applied cheese-making practices among dairies and to determine how the cheese-making technology-related dimensions discriminate among the set of dairies, building a spatial representation of the relative positioning of dairies considered for the survey. To comply with the rules of multiple linear discriminant analysis (MLDA), the number of predictor variables was reduced from 27 to 8 . As for the assumptions of discriminant analysis, it is generally suggested that it is desirable to meet specific multivariate normality and multivariate collinearity conditions for proper application of the technique. Normality of the means distribution was assessed by ensuring that no data skewness value exceeds 1.96. Further, variance inflation factor was used as a test for inconsequential collinearity, with a common cut off threshold fixed at 10.0.

Discriminant functions were obtained by fixing $\mathrm{F}$ values to the default values of the package SPSS (version 20.0; IBM Corp., Armonk, NY), that is 3.84 for entry and 2.71 for removal. To assess the level of significance of the discriminant functions, Wilks' Lambda has been used in this study. The common criterion of 0.05 or beyond significance level was used. The following step was used to assess classification accuracy. As the dependent variable is nonmetric, each observation must be assessed as to whether it was correctly classified. The hit-ratio was satisfactory for proving discriminant power of the functions. Finally, a graphic representation of the discriminant functions that displays the group centroids (dairy groupings) on the first 2 discriminant functions is provided.

\section{Characterization of Average Cheese-Making Parameters of Each of the 4 Groups of Dairies and Relations with the Surface Aspect of the Fresh Cheese Curds}

Descriptive statistics of all 27 cheese-making parameters (Table 1) for each of the 4 groups of dairies were obtained, and the significance of the differences among mean values for each parameter was evaluated by ANOVA using a Bonferroni $(P<0.05)$ post hoc test.
Similarly, the significance of differences among mean values of the aspect features of curds surface were taken into consideration.

\section{RESULTS AND DISCUSSION}

\section{Grouping of PR-RE Dairies According to Specific Cheese-Making Technologies by Means of MLDA}

To test the feasibility of discrimination among PR-RE dairies based on dairy-specific cheese-making technologies, MLDA was performed. The reduction of the number of predictor variables was addressed via a brainstorming session arranged with a group of experts, asking them to rank the 27 parameters in order of importance. As a result, the independent or predictor variables were reduced from 27 to 8 (Table 1), and 8 canonical functions were calculated and found to be statistically significant. The first 2 functions gave reason for $75 \%$ of the variance (Table 2).

To assess the predictive accuracy of the classification of the dairies, each observation was assessed as to whether it was correctly classified. The hit-ratio revealed that $75.7 \%$ of the 1,175 reports were correctly assigned to the dairy where they were monitored.

The standardized coefficients of canonical discriminant functions represented in Table 3 suggest that the first 2 discriminant functions appear to be measuring the following predictor variables:

1. gelation time $(+)$ versus duration of cutting $(-)$, and

2. the combination of gelation time and duration of cutting $(+)$ versus the combination of amount of rennet and time of coagulum hardening $(-)$.

The graphic representation of resulting group centroids (Figure 1) helps to identify the distribution of each of the 30 dairies in the 4 quadrants of the plane and build-up 4 groups, each corresponding to a quadrant.

\section{Cheese-Making Parameters Characterizing Each of the 4 Groups of Dairies}

The average values $( \pm \mathrm{SD})$ of all the 27 cheese-making parameters for each group of dairies are reported in Table 1. (A flowchart is presented in the Supplementary Material: http://dx.doi.org/10.3168/jds.2013-7022.) The data show in detail the cheese-making parameters actually adopted by PR-RE dairies, demonstrating some aspects (e.g., the ratio between cutting time and coagulation time or the rate of curd cooking) frequently ignored by literature. The overall data confirmed that 
Table 1. Comparison of cheese-making technology parameters (means $\pm \mathrm{SD}$ ) of each dairy group resulting from multiple linear discriminant analysis and the overall mean values of technological parameters

\begin{tabular}{|c|c|c|c|c|c|}
\hline Item & Group A $(\mathrm{n}=7)$ & Group B $(\mathrm{n}=10)$ & Group C $(\mathrm{n}=6)$ & Group D $(\mathrm{n}=7)$ & Total \\
\hline Skim milk from evening milking $(\mathrm{kg})$ & $528.87^{\mathrm{a}} \pm 82.59$ & $517.80^{\mathrm{ab}} \pm 37.52$ & $511.75^{\mathrm{bc}} \pm 65.61$ & $504.45^{\mathrm{cd}} \pm 28.08$ & $515.48 \pm 56.13$ \\
\hline Temperature of milk after creaming $\left({ }^{\circ} \mathrm{C}\right)$ & $17.03^{\mathrm{a}} \pm 1.54$ & $17.02^{\mathrm{a}} \pm 2.06$ & $17.58^{\mathrm{b}} \pm 2.19$ & $15.91^{\mathrm{c}} \pm 2.58$ & $16.90 \pm 2.21$ \\
\hline Milk pH & $6.70^{\mathrm{a}} \pm 0.02$ & $6.71^{\mathrm{a}} \pm 0.03$ & $6.73^{\mathrm{b}} \pm 0.03$ & $6.71^{\mathrm{c}} \pm 0.03$ & $6.71 \pm 0.03$ \\
\hline Whole milk from morning milking $(\mathrm{kg})$ & $539.03^{\mathrm{a}} \pm 54.52$ & $533.59^{\mathrm{ab}} \pm 32.62$ & $526.59^{\mathrm{bc}} \pm 49.04$ & $544.24^{\mathrm{a}} \pm 32.51$ & $535.62 \pm 42.65$ \\
\hline Temperature of milk arriving at the dairy $\left({ }^{\circ} \mathrm{C}\right)$ & $20.43^{\mathrm{a}} \pm 1.60$ & $19.69^{\mathrm{b}} \pm 1.51$ & $21.20^{\mathrm{c}} \pm 2.68$ & $20.99^{\mathrm{ac}} \pm 4.34$ & $20.51 \pm 2.78$ \\
\hline Milk pH & $6.70^{\mathrm{a}} \pm 0.02$ & $6.71^{\mathrm{b}} \pm 0.02$ & $6.71^{\mathrm{bc}} \pm 0.04$ & $6.70^{\mathrm{a}} \pm 0.03$ & $6.70 \pm 0.03$ \\
\hline Total amount of milk into the vat $(\mathrm{kg})$ & $1.067 .94^{\mathrm{a}} \pm 76.64$ & $1,051.39^{\mathrm{b}} \pm 40.60$ & $1.038 .34^{\mathrm{c}} \pm 43.72$ & $1,048.69^{\mathrm{bcd}} \pm 45.55$ & $1,051.11 \pm 52.86$ \\
\hline Milk temperature into the vat $\left({ }^{\circ} \mathrm{C}\right)$ & $18.79^{\mathrm{a}} \pm 1.35$ & $18.62^{\mathrm{ab}} \pm 1.40$ & $19.90^{\mathrm{c}} \pm 1.63$ & $18.74^{\mathrm{ab}} \pm 2.79$ & $18.99 \pm 1.93$ \\
\hline Milk pH & $6.70^{\mathrm{a}} \pm 0.02$ & $6.71^{\mathrm{b}} \pm 0.02$ & $6.71^{\mathrm{bc}} \pm 0.04$ & $6.71^{\mathrm{bd}} \pm 0.03$ & $6.71 \pm 0.03$ \\
\hline Whey starter (WS) acidity $\left({ }^{\circ} \mathrm{SH}^{1} / 50 \mathrm{~mL}\right)$ & $30.44^{\mathrm{a}} \pm 1.65$ & $30.71^{\mathrm{ab}} \pm 1.48$ & $30.41^{\mathrm{abc}} \pm 1.52$ & $30.14^{\mathrm{ac}} \pm 1.53$ & $30.45 \pm 1.55$ \\
\hline Milk acidity increase after WS addition ( $\left.{ }^{\circ} \mathrm{SH} / 10\right)$ & $8.54^{\mathrm{a}} \pm 0.85$ & $7.89^{\mathrm{b}} \pm 0.39$ & $7.91^{\mathrm{b}} \pm 0.54$ & $7.83^{\mathrm{b}} \pm 0.44$ & $8.02 \pm 0.62$ \\
\hline Whey starter quantity $(\mathrm{kg} / 100 \mathrm{~kg}$ of milk) & $35.17^{\mathrm{a}} \pm 4.22$ & $31.46^{\mathrm{b}} \pm 2.05$ & $31.31^{\mathrm{b}} \pm 3.46$ & $31.15^{\mathrm{b}} \pm 2.29$ & $32.27 \pm 3.51$ \\
\hline Milk pH after whey starter addition ${ }^{2}$ & $6.36^{\mathrm{a}} \pm 0.03$ & $6.39^{\mathrm{b}} \pm 0.04$ & $6.41^{\mathrm{c}} \pm 0.04$ & $6.41^{\mathrm{c}} \pm 0.03$ & $6.39 \pm 0.04$ \\
\hline Normalized amount of rennet ${ }^{2}(\mathrm{~g} / 100 \mathrm{~kg}$ of milk) & $4.11^{\mathrm{a}} \pm 0.63$ & $3.42^{\mathrm{b}} \pm 0.29$ & $5.02^{\mathrm{c}} \pm 1.38$ & $3.67^{\mathrm{d}} \pm 0.54$ & $4.01 \pm 1.01$ \\
\hline Milk temperature at renneting ${ }^{2}\left({ }^{\circ} \mathrm{C}\right)$ & $33.51^{\mathrm{a}} \pm 0.53$ & $33.81^{\mathrm{b}} \pm 0.34$ & $33.80^{\mathrm{b}} \pm 0.37$ & $33.84^{\mathrm{b}} \pm 0.28$ & $33.75 \pm 0.40$ \\
\hline Gelation time $^{2}(\mathrm{GT} ; \mathrm{s})$ & $551.72^{\mathrm{a}} \pm 63.14$ & $704.81^{\mathrm{b}} \pm 44.16$ & $509.14^{\mathrm{c}} \pm 35.24$ & $659.57^{\mathrm{d}} \pm 74.42$ & $615.11 \pm 97.83$ \\
\hline Time of coagulum hardening ${ }^{2}$ (HT; s) & $74.00^{\mathrm{a}} \pm 31.66$ & $117.79^{\mathrm{b}} \pm 22.86$ & $89.90^{\mathrm{c}} \pm 28.93$ & $132.38^{\mathrm{d}} \pm 27.17$ & $105.54 \pm 35.17$ \\
\hline Ratio HT to GT & $0.13^{\mathrm{a}} \pm 0.05$ & $0.17^{\mathrm{b}} \pm 0.03$ & $0.18^{\mathrm{c}} \pm 0.06$ & $0.20^{\mathrm{d}} \pm 0.04$ & $0.17 \pm 0.05$ \\
\hline Duration of cutting $^{2}(\mathrm{~s})$ & $214.59^{\mathrm{a}} \pm 45.82$ & $151.73^{\mathrm{b}} \pm 34.29$ & $129.33^{\mathrm{c}} \pm 21.08$ & $115.93^{\mathrm{d}} \pm 13.36$ & $151.04 \pm 47.04$ \\
\hline Ratio cutting time to coagulation time $(\mathrm{GT}+\mathrm{HT})$ & $0.35^{\mathrm{a}} \pm 0.07$ & $0.19^{\mathrm{b}} \pm 0.05$ & $0.22^{\mathrm{c}} \pm 0.04$ & $0.15^{\mathrm{d}} \pm 0.02$ & $0.22 \pm 0.08$ \\
\hline Curd temperature at the end of cutting $\left({ }^{\circ} \mathrm{C}\right)$ & $33.60^{\mathrm{a}} \pm 0.63$ & $34.88^{\mathrm{b}} \pm 1.32$ & $34.01^{\mathrm{c}} \pm 0.77$ & $34.44^{\mathrm{d}} \pm 0.84$ & $34.28 \pm 1.07$ \\
\hline Curd temperature at the end of cooking ${ }^{2}\left({ }^{\circ} \mathrm{C}\right)$ & $54.99^{\mathrm{a}} \pm 0.25$ & $55.19^{\mathrm{b}} \pm 0.26$ & $54.93^{\mathrm{c}} \pm 0.26$ & $55.17^{\mathrm{b}} \pm 0.25$ & $55.08 \pm 0.28$ \\
\hline Duration of curd cooking $^{2}(\mathrm{~s})$ & $267.89^{\mathrm{a}} \pm 87.57$ & $380.33^{\mathrm{b}} \pm 62.39$ & $276.60^{\mathrm{a}} \pm 54.21$ & $304.47^{\mathrm{c}} \pm 78.53$ & $314.46 \pm 84.42$ \\
\hline Rate of curd cooking $\left({ }^{\circ} \mathrm{C} / \mathrm{min}\right)$ & $5.04^{\mathrm{a}} \pm 1.81$ & $3.29^{\mathrm{b}} \pm 0.64$ & $4.51^{\mathrm{c}} \pm 1.01$ & $4.15^{\mathrm{d}} \pm 0.80$ & $4.14 \pm 1.27$ \\
\hline Overall time from rennet addition to cooking end (TT; s) & $1,094.73^{\mathrm{a}} \pm 121.04$ & $1,353.91^{\mathrm{b}} \pm 73.53$ & $1,002.28^{\mathrm{c}} \pm 66.56$ & $1,209.13^{\mathrm{d}} \pm 116.66$ & $1,181.04 \pm 166.58$ \\
\hline Ratio TT to GT & $1.99^{\mathrm{a}} \pm 0.14$ & $1.92^{\mathrm{b}} \pm 0.08$ & $1.97^{\mathrm{a}} \pm 0.09$ & $1.84^{\mathrm{c}} \pm 0.09$ & $1.93 \pm 0.12$ \\
\hline Time of cooked curd lying under hot whey (min) & $60.37^{\mathrm{a}} \pm 8.07$ & $70.05^{\mathrm{b}} \pm 8.20$ & $66.70^{\mathrm{c}} \pm 9.87$ & $60.11^{\mathrm{a}} \pm 6.74$ & $64.84 \pm 9.35$ \\
\hline
\end{tabular}

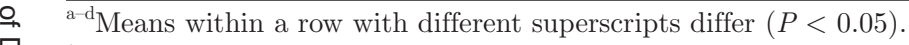

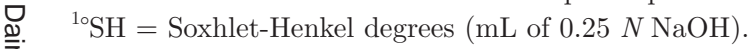

${ }^{2}$ Variables used for multiple linear discriminant analysis. 
Table 2. Eigenvalues of the canonical functions deriving from multiple linear discriminant analysis

\begin{tabular}{lcccc}
\hline Function & Eigenvalue & $\begin{array}{c}\text { Percentage } \\
\text { of variance }\end{array}$ & $\begin{array}{c}\text { Cumulative percentage } \\
\text { of variance }\end{array}$ & $\begin{array}{c}\text { Canonical } \\
\text { correlation }\end{array}$ \\
\hline 1 & 8.855 & 45.2 & 45.2 & 0.948 \\
2 & 5.842 & 29.8 & 75.0 & 0.924 \\
3 & 1.961 & 10.0 & 85.0 & 0.814 \\
4 & 1.043 & 5.3 & 90.3 & 0.714 \\
5 & 0.803 & 4.1 & 94.4 & 0.667 \\
6 & 0.587 & 3.0 & 97.4 & 0.608 \\
7 & 0.345 & 1.8 & 99.1 & 0.507 \\
8 & 0.171 & 0.9 & 100.0 & 0.382 \\
\hline
\end{tabular}

dairies adopted cheese-making parameters coherent with those described to date in the literature (Pecorari et al., 2003; Mucchetti and Neviani, 2006; Tosi et al., 2006; Pecorari et al., 2009; Iezzi et al., 2012; Gatti et al., 2014). However, each dairy or group of them used a specific combination of the cheese-making parameters.

Amount of rennet, gelation time, time of coagulum hardening before cutting, duration of the cutting of the coagulum, temperature of the curd grains immerged in the whey at the end of cutting, and rate of curd grains cooking are the cheese-making parameters that were significantly different $(P<0.001)$ for the 4 groups of dairies. As a consequence, the duration of cheesemaking from rennet addition to the end of curd cooking was also significantly different.

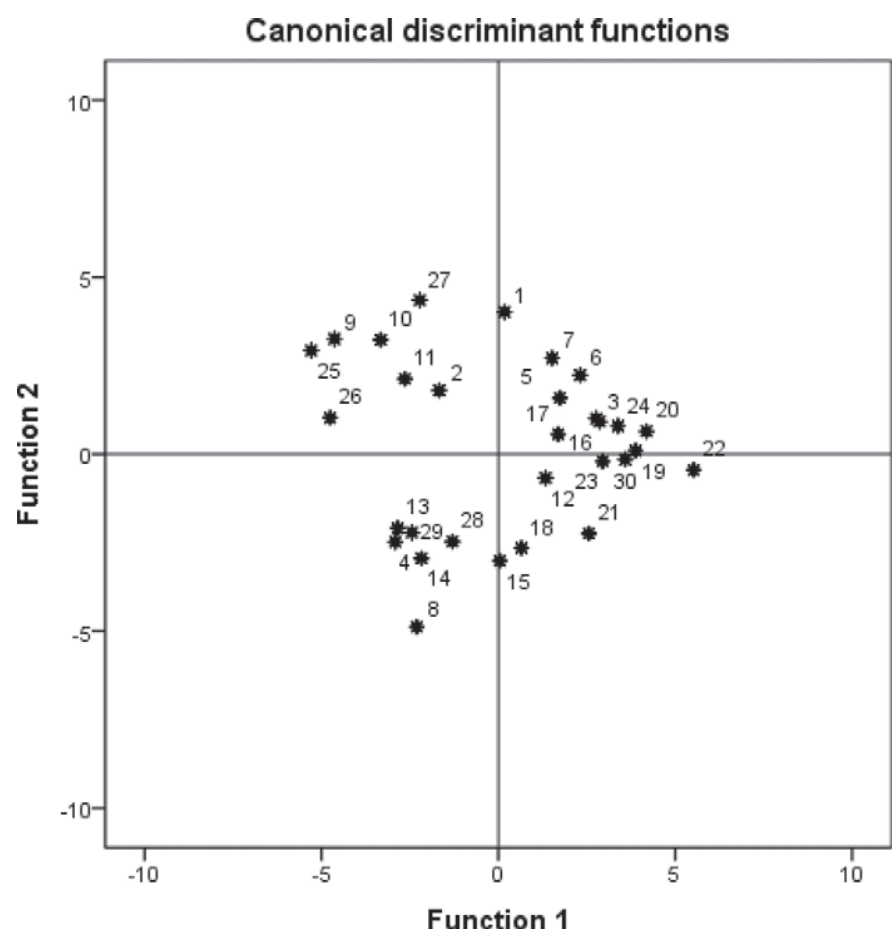

Figure 1. Graphic representation of the dairy groups' centroids based on the first 2 discriminant functions from multiple linear discriminant analysis.
Dairies belonging to group A can be identified by the highest increase of milk acidity due to the addition of the highest amount of whey starter. As follows, milk coagulation was characterized by a relatively short time of milk gelation followed by the shortest time of coagulum hardening, leading to cutting of the softest coagulum. Other discriminant traits were the longest duration of the operation of coagulum cutting and the fastest curd grain cooking time. However, group A was the only group of the 4 that did not start to cook the curd grains during the cutting operation. The ratio of cutting time to the overall coagulation time was the highest. The ratio of overall cheese-making time to gelation time for the dairies of group A was $1.99 \pm 0.14$, and it was the highest; this means that the duration of all the cheese vat operations, from the cutting of coagulum to the end of curd cooking, was fundamentally equal to that requested for the gelation time.

Dairies belonging to group B used the lowest amount of rennet, and, consequently, the time of milk gelation was the longest. Also, the curd grain cooking was the slowest, despite dairies starting to cook during the cutting operation. As a result, group B is characterized by the longest time of operation from rennet addition to end of cooking. Dairies belonging to group $\mathrm{C}$ were identified by the shortest time of cheese-making, and milk coagulation was characterized by the shortest gelation time due to the highest amount of rennet added. Finally, group D was distinguished by the longest time of coagulum hardening and the shortest cutting time of the coagulum, respectively. This generates the highest ratio between hardening time and gelation time, leading to a firm coagulum, but, at the same time, the ratio between the overall cheese-making time and the gelation time was the lowest $(1.84 \pm 0.09)$, demonstrating the quickness of the operations after the gel formation.

\section{Relations Among the 4 Groups of Dairies and the Surface Aspect of the Fresh PR-RE Cheese Curds}

The aspect of the surface of the cheese curd was evaluated by trained technicians immediately after extraction 
Table 3. Standardized coefficients of canonical discriminant functions deriving from multiple linear discriminant analysis

\begin{tabular}{|c|c|c|c|c|c|c|c|c|}
\hline Item & \multicolumn{8}{|c|}{ Function } \\
\hline Milk pH after whey starter addition & 0.127 & -0.319 & -0.031 & -0.328 & 0.337 & 0.008 & 0.816 & -0.005 \\
\hline Gelation time (s) & 0.771 & 0.398 & 0.082 & -0.196 & 0.328 & -0.515 & -0.213 & 0.121 \\
\hline Time of coagulum hardening (s) & 0.182 & -0.357 & 0.684 & 0.062 & -0.363 & 0.632 & 0.003 & -0.036 \\
\hline Milk temperature at renneting $\left({ }^{\circ} \mathrm{C}\right)$ & 0.171 & -0.141 & 0.050 & 0.731 & 0.644 & 0.042 & -0.079 & -0.089 \\
\hline Duration of curd cooking (s) & 0.059 & 0.215 & -0.437 & -0.063 & 0.105 & 0.928 & -0.024 & 0.151 \\
\hline
\end{tabular}

from cheese vat. Out of the 5 scale levels, only the first 4 (from very rough and lined, or rigata to smooth) were positively judged by PR-RE cheese-makers. (A picture representing the surface of the curd evaluated as rigata is presented in the Supplementary Material at http:// dx.doi.org/10.3168/jds.2013-7022). Data collected from potentially defective curds (34/1,175 samples), assigned to item E (surface irregularly rough with cavities), were discharged to minimize their influence on comparison among groups.

Hence, according to PR-RE cheese-makers, we intuitively infer that the smaller the average grain size and the narrower their distribution, the smoother the cheese curd surface, despite the wrinkled aspect and the irregular shape of each curd grain. Conversely, it became evident an inverse correlation exists between the risk of too small grains and average size. The smallest grains risk being too dehydrated upon cooking because of their higher surface to volume ratio, thus losing the propensity to aggregate each other and resulting in cohesive and elastic cheese curds (Parisi, 1966). The smallest grains, also described as powder, are frequently recovered in the whey (Mariani et al., 2000). Conversely, larger grains, with a projected area up to 10 times the mean value (Iezzi et al., 2012), lead to a rougher surface, as they have poor melting properties because of their high cooking temperature (Mariani et al., 2000; Gobbetti, 2007). In addition, they may hardly drive a complete whey drainage and, as a consequence, the risk of local defects (excess of acidification, early blowing) due to local whey retention is higher (Parisi, 1966).

Further investigations were carried out to support the preference choice between a cheese curd with a rigata or a giusta surface. We found a generalized agreement on behalf of cheese-makers of the PR-RE area producing both varieties that, within 2 or $3 \mathrm{~d}$ (before salting), the curd surface has to be smooth and with homogeneous distribution of the moisture content signaled by corresponding homogeneous coloration of the whole surface. Cheese makers choices are to a large extent driven by their skills in managing alternative risks (too smooth vs. too rigata); excessively smooth curds at extraction tend to be less elastic and cohesive and to have a higher risk of surface defects during ripening, whereas excessively rough and striped curds will probably have too-moist residual spots, with the consequent risk of incorrect whey drainage and defective outcome. Quadri (1959) considered it more advisable to produce a curd with a lined aspect than a too smooth (finita) one, believing a positive outcome more probable in the first case. In the second case, too early of whey separation leads to excessively small cheese curd grains with poor ability to join together, historically considered an index of a poor outcome (Cattaneo, 1837).

The results of judgments made by the technicians (Table 4) showed that the 4 groups of dairies were characterized by the production of cheese curds with a significantly different average value of the aspect of the surface, considering both the mouth and the side. Cheese curds from dairies belonging to group A scored lowest in roughness attributes both for the mouth and the side. Conversely, the rough and lined attribute was largely predominant as for cheeses in group D dairies.

The average ratio less than unity reported in Table 4 indicated that the aspect of the side surface is usually slightly less lined and rough than the mouth one, but this behavior was particularly evident only for curds of group A dairies $(0.73 \pm 0.16)$. The aspect of cheese curd surface immediately after extraction depends on how curd grains were obtained and sedimentation occurred. Parisi (1966) hypothesized a strict correlation between size of curd grain and sedimentation rate. However, in addition to the large distribution of PR-RE cheese curd grains size (from 0.1 to $28.9 \mathrm{~mm}^{2}$ of projected area) determined by cutting and cooking conditions (Iezzi et al., 2012), a plurality of factors interact with sedimentation rate and surface aspect (i.e., density of grains, surface properties, and ability of curd grains to mutually coalesce). As a consequence, it is not possible to accurately foresee the sedimentation rate of curd grains using the Stokes equation because of the high concen- 
Table 4. Descriptive statistics of cheese curd surface (side or fianco and upper surface or bocca) immediately after extraction from cheese vat belonging to the groups of dairies originated from multiple linear discriminant analysis $^{1}$

\begin{tabular}{|c|c|c|c|c|c|}
\hline \multirow[b]{2}{*}{ Item } & \multirow[b]{2}{*}{$\begin{array}{l}\text { Group } \\
\text { of dairies }\end{array}$} & \multirow[b]{2}{*}{$\mathrm{N}$} & \multirow[b]{2}{*}{ Mean \pm SD } & \multicolumn{2}{|c|}{$95 \% \mathrm{CI}$} \\
\hline & & & & $\begin{array}{l}\text { Lower } \\
\text { limit }\end{array}$ & $\begin{array}{l}\text { Upper } \\
\text { limit }\end{array}$ \\
\hline \multirow[t]{5}{*}{ Side or fianco } & A & 221 & $2.56^{\mathrm{a}} \pm 0.50$ & 2.49 & 2.62 \\
\hline & $\mathrm{B}$ & 366 & $1.97^{\mathrm{b}} \pm 0.39$ & 1.93 & 2.01 \\
\hline & $\mathrm{C}$ & 272 & $2.20^{\mathrm{c}} \pm 0.64$ & 2.12 & 2.27 \\
\hline & $\mathrm{D}$ & 282 & $1.75^{\mathrm{d}} \pm 0.57$ & 1.69 & 1.82 \\
\hline & All the dairies & 1,141 & $2.08 \pm 0.59$ & 2.05 & 2.12 \\
\hline \multirow[t]{5}{*}{ Upper surface or bocca } & A & 221 & $3.58^{\mathrm{a}} \pm 0.69$ & 3.49 & 3.67 \\
\hline & B & 366 & $2.13^{\mathrm{b}} \pm 0.58$ & 2.07 & 2.19 \\
\hline & $\mathrm{C}$ & 272 & $2.35^{\mathrm{c}} \pm 0.83$ & 2.25 & 2.45 \\
\hline & $\mathrm{D}$ & 282 & $1.88^{\mathrm{d}} \pm 0.72$ & 1.80 & 1.96 \\
\hline & All the dairies & 1,141 & $2.40 \pm 0.93$ & 2.35 & 2.46 \\
\hline \multirow[t]{5}{*}{ Ratio of fianco to bocca } & A & 221 & $0.73^{\mathrm{a}} \pm 0.16$ & 0.71 & 0.74 \\
\hline & $\mathrm{B}$ & 366 & $0.96^{\mathrm{b}} \pm 0.20$ & 0.94 & 0.98 \\
\hline & $\mathrm{C}$ & 272 & $0.99^{\mathrm{b}} \pm 0.31$ & 0.96 & 1.03 \\
\hline & $\mathrm{D}$ & 282 & $0.99^{\mathrm{b}} \pm 0.30$ & 0.95 & 1.02 \\
\hline & All the dairies & 1,141 & $0.93 \pm 0.27$ & 0.91 & 0.95 \\
\hline
\end{tabular}

${ }^{\mathrm{a}-\mathrm{d}}$ Means within a column with different superscripts differ $(P<0.01)$.

${ }^{1}$ Scale items corresponded in numerical order to "very rough and lined" (1), "rough and lined" (2), "slight rough and lined" (3), or "smooth" (4). The scale item "irregularly rough with cavities" (5), accounting for 34 out 1,175 cheese-making trials, was excluded from the evaluation because it is considered as defective.

tration and uneven properties of the particles (Concha, 2009) that are in unsteady state. Grains tend to aggregate more quickly with each other when stirring is stopped and progressive whey separation modifies curd grain density; this property is determined by chemical composition (Iezzi et al., 2013).

Parmigiano Reggiano cheese makers adapt technological parameters on a daily basis in trial and error fashion. Such an incremental effort is finalized to obtain cheese curd grains with overall characteristics able to retrieve fresh curds with sufficiently defined properties that are thought of as optimal drivers for satisfactory cheese outcomes at the end of ripening. Future research guidelines will be directed toward exploring the nature of the relations between these parameters and the resulting characteristics of PR-RE cheese. If a sufficiently strong correlation can be demonstrated, research on possible curd structure-oriented improvements of cheese-making technology will deserve further development and investigation, as the operational effectiveness of PR-RE dairies will be able to largely benefit from the availability of sound and early process markers.

\section{CONCLUSIONS}

This study allowed for identification of 4 distinct groups of PR-RE dairies adopting specific cheese-making technologies, obtaining cheese curds with different surface aspects immediately after extraction from cheese vat. Cutting the coagulum when it is very soft for a longer time and a faster cooking of the cheese curd grains tended to be associated with a less rough appearance of the surface of the curd (group A), whereas the opposite, cutting the coagulum when it is firm for a shorter time, led to a curd with a more rough surface (group D). A widespread and consolidated belief among cheese makers is that curd features play a pivotal role as potential markers of the outcome of the whole cheese-making process. To date, however, no evidence has been provided about the scientific justification and strength of such an empirical practice.

\section{ACKNOWLEDGMENTS}

This research was funded by Regione Emilia-Romagna (Bologna, Italy) and Consorzio del Formaggio Parmigiano-Reggiano. The authors thank technicians from Artest SpA (Modena, Italy), Centro Servizi per l'Agroalimentare (Parma, Italy) and Salchim (Cavriago, Reggio Emilia, Italy) for their valuable contribution to data collection.

\section{REFERENCES}

Bittante, G., A. Cecchinato, N. Cologna, M. Penasa, F. Tiezzi, and M. De Marchi. 2011. Factors affecting the incidence of first-quality wheels of Trentingrana cheese. J. Dairy Sci. 94:3700-3707.

Cattaneo, L. 1837. Il caseificio o la fabbricazione dei formaggi. Tipografia Molina. Milano, Italy.

Concha, F. 2009. Settling velocities of particulate systems. KONA $27: 18-37$.

European Commission. 2013. Parmigiano Reggiano denomination information. DOOR, Agriculture and Rural Development. Accessed Oct. 7, 2013. http://ec.europa.eu/agriculture/quality/door/registered Name.html?denominationId $=518$. 
Gatti, M., B. Bottari, C. Lazzi, E. Neviani, and G. Mucchetti. 2014. Invited review: Microbial evolution in raw milk, long-ripened cheeses produced using undefined natural starters. J. Dairy Sci. 97:573-591. http://dx.doi.org/10.3168/jds.2013-7187.

Gatti, M., C. Lazzi, L. Rossetti, G. Mucchetti, and E. Neviani. 2003. Biodiversity in Lactobacillus helveticus strains present in natural whey starter used for Parmigiano-Reggiano cheese. J. Appl. Microbiol. 95:463-470.

Gobbetti, M. 2007. What causes the traditional grainy texture of Italian Grana-type cheeses? Page 209 in Cheese Problems Solved. P. L. H. McSweeney, ed. Woodhead Publishing Ltd., Cambridge, UK.

Iezzi, R., F. Locci, R. Ghiglietti, C. Belingheri, S. Francolino, and G. Mucchetti. 2012. Parmigiano-Reggiano and Grana Padano cheese curd grains size and distribution by image analysis. Lebenson. Wiss. Technol. 47:380-385.

Iezzi, R., F. Locci, and G. Mucchetti. 2013. Cheese true density prediction by linear equations. J. Food Process Eng. 36:462-469.

Malacarne, M., A. Summer, P. Formaggioni, P. Franceschi, S. Sandri, M. Pecorari, P. Vecchia, and P. Mariani. 2008. Dairy maturation of milk used in the manufacture of Parmigiano-Reggiano cheese: Effects on physico-chemical characteristics, rennet coagulation aptitude and rheological properties. J. Dairy Res. 75:218-224.

Mariani, P., A. Summer, P. Formaggioni, M. Malacarne, and B. Battistotti. 2000. Rilievi sui principali requisiti tecnologico-caseari del latte per la produzione di formaggio Grana. Annali Facoltà Medicina Veterinaria. Università di Parma vol XX. Accessed Oct. 3, 2013. http://www.unipr.it/arpa/facvet/annali/2000/mariani/ mariani.htm.
Monnet, J. C., F. Berodier, and P. M. Badot. 2000. Characterization and localization of a cheese georegion using edaphic criteria (Jura Mountains, France). J. Dairy Sci. 83:1692-1704.

Mucchetti, G., and E. Neviani. 2006. Microbiologia e tecnologia lattiero casearia. Qualità e Sicurezza. Tecniche Nuove Editore, Milano, Italy

Noel, Y., M. Zannoni, and E. A. Hunter. 1996. Texture of Parmigiano Reggiano cheese: Statistical relationship between rheology and sensory varieties. Lait 76:243-254.

Parisi, O. 1966. Il Formaggio Grana. S.T.E.M. Mucchi, Modena, Italy. Pecorari, M. 2011. Il Parmigiano-Reggiano. La qualità e i difetti. Grafiche Step editrice, Parma. Italy.

Pecorari, M., G. Gambini, A. Pecorari, F. Masotti, J. Hogenboom, L. Pellegrino, S. Ghidini, M. Malacarne, and P. Mariani. 2009. L'utilizzo di caldaie di rame o di acciaio: Effetti sulla tecnologia e sulle caratteristiche qualitative del Parmigiano-Reggiano. Sci. Tecn. Latt. Cas. 60:97-118.

Pecorari, M., G. Gambini, P. Reverberi, and A. Caroli. 2003. Incidenza di alcuni fattori tecnologici sulla della glicolisi del ParmigianoReggiano. Sci. Tecn. Latt. Cas. 54:287-299.

Quadri, P. 1959. Norme tecniche per la trasformazione del latte in Parmigiano-Reggiano e per la produzione del burro. Tecnica del Latte 9:10-13.

Tosi, F., S. Sandri, E. Fossa, A. Summer, and M. S. Mariani. 2006. Variazioni stagionali delle caratteristiche analitiche del sieroinnesto naturale utilizzato nelle produzione di Parmigiano-Reggiano durante il 2004. Sci. Tecn. Latt. Cas. 57:87-104. 